\title{
CORPO E NOVIDADE PUBERAL
}

Olivier Ouvry

Olivier Ouvry
Psiquiatra,
psicanalista. Mestre
conferencista.
Tradução
Pedro Henrique Bernardes
Rondon
Psicanalista,
membro efetivo
da Sociedade de
Psicanálise da
Cidade do Rio de
Janeiro (SPCRJ).
Membro efetivo
da Associação
Brasileira para o
Estudo da Psicologia
Psicanalítica do Self
(Abepps).

Olivier Ouvry

Psiquiatra,

psicanalista. Mestre

Rondon

Psicanalista,

membro efetivo

da Sociedade de

Psicanálise da

Cidade do Rio de

Janeiro (SPCRJ).

Membro efetivo

Brasileira para o

da Psicologia

(Abepps).
RESUMO: As transformações corporais na adolescência causam efração na criança, além de suas simples manifestações formais. A novidade puberal se impõe, de fato, como real puberal (real no sentido lacaniano), qualificada de Feminino ou de advento do Outro sexo. Esta perspectiva teórica se inscreve na pura continuidade dos textos de Freud, como é revelado por uma releitura permitida pelas contribuições do estruturalismo e de Lacan. Duas situações clínicas (de fato, dois personagens de filme) ilustram este relato.

Palavras-chave: Novidade puberal, real puberal, estruturalismo, Lacan, Freud.

ABSTRACT: Body and pubertal novelty. Body transformations in adolescence break in the child besides their simple formal disclosures. The pubertal novelty imposes itself as the real pubertal (real in the Lacanian sense), qualified as Feminine or coming from the other gender. This theoretical perspective inscribes itself in the pure continuity of the Freudian texts, as it is revealed by a new reading permitted by Lacan's and structuralism contributions. Two clinical situations (in fact two movie characters) will illustrate this report.

Keywords: Pubertal novelty, pubertal real, structuralism, Lacan, Freud. 
A questão do corpo na adolescência introduz oportunamente a noção da falta. Essa é central na teorização do puberal (lembramos que a adolescência não é um conceito analítico) — assim como o é em toda a teoria analítica. Vamos abordá-la por diversos caminhos, mas nunca num desejo de diluir sua importância estrutural, como princípio do processo da adolescência. Veremos também seus efeitos no campo da psicopatologia do adolescente a partir de uma clínica que vamos extrair de dois filmes, um dos quais recente e bastante difundido.

Para isso, partiremos de uma proposição: na adolescência, o corpo deve ser colocado no registro do impossível. De fato:

- É desse corpo que vem o fim do período infantil: ele impõe uma novidade radical que muda tudo o que era anteriormente (fazendo aparecer o desejo sexual por alguém mais, estranho, fobogênico - e não mais pelos monstros da infância, figuras parentais arcaicas). É essa novidade que destitui aqueles que eram as garantias desse mundo normatizado do infantil: os pais. Vamos falar aqui de um impossível imaginário.

- Esse corpo, entretanto, vem também impor uma novidade no registro do real, no sentido lacaniano — isto é, de um impossível, no simbólico. De fato, não há significante que venha ecoar a novidade puberal. É nesse sentido que ela é radical.

É uma novidade porque os pais não possibilitaram à criança prever — e não é para menos: eles mesmos se veem apanhados nessa ignorância! A isso Lacan denominou ausência de relação sexual.

De fato, não há relação sexual na linguagem, uma vez que só há um único significante para os dois sexos: o falo. Assim, nada vem permitir uma cópula, no sentido gramatical do termo, entre o que seria de uma instância masculina e de uma instância feminina na língua, compreendida como aquela que estrutura o inconsciente. Portanto, nada pode ser dito sobre isso.

A novidade puberal se torna então o Outro sexo, com um O maiúsculo porque radicalmente outro em relação àquele que ordenava e normatizava o infantil (o fálico), e porque ausente do mundo do Infantil. Trata-se do Feminino. Isso é o que pode ser deduzido de uma leitura ao pé da letra dos textos freudianos a propósito da vida sexual, tal como pretendemos demonstrar.

\section{PERSPECTIVA HISTÓRICA}

Retomamos esses pontos a partir dos textos de Freud. A efração puberal se anuncia pela novidade fisiológica que impõe ao sujeito, pelo corpo, uma nova distribuição de jogo, desconhecida do infantil. Esta foi introduzida por Freud em 1905 (FREUD, 1905/1987). Desde essa época ele fala de duas noções: a prevalência do 
masculino no infantil; e o deslocamento das zonas erógenas do clitóris para a vagina como característica da novidade puberal — numa linguagem muito descritiva, mas muito intuitiva, do que ulteriormente terá uma tradução teórica.

No capítulo “Diferenciação do homem e da mulher”, ele indica com exatidão:

“É sabido que somente na puberdade se estabelece a separação nítida dos caracteres masculinos e femininos [...]. As predisposições masculinas e femininas certamente já são facilmente reconhecíveis na infância [...]. Porém, a atividade autoerótica das zonas erógenas é a mesma para os dois sexos e, em virtude dessa concordância, a possibilidade de uma diferença dos sexos tal como a que se estabelece após a puberdade, é suprimida durante toda a infância. Levando em consideração as manifestações sexuais autoeróticas e masturbatórias, poder-se ia formular a tese seguinte: a sexualidade das meninas pequenas tem caráter inteiramente masculino. E mais do que isso, se fôssemos capazes de dar um conteúdo mais preciso aos conceitos de 'masculino e de feminino', seria mesmo possível sustentar que a libido é, de maneira regular e de acordo com as leis, de natureza masculina...” (FREUD, 1905/1987, p.160-161)

Assim, não há senão o masculino no infantil, o que é posto em conexão, por Freud, com a libido de natureza exclusivamente masculina.

Quanto à menina e ao aparecimento de uma especificidade que lhe seria própria, isso terá lugar apenas na adolescência:

“Tudo o que minha experiência me ensinou acerca da masturbação das meninas pequenas se referia ao clitóris, e não às partes do aparelho genital externo que são importantes para as funções sexuais ulteriores. [...] A puberdade [...] se caracteriza, na menina, por uma nova onda de recalcamento que afeta precisamente a atividade clitoridiana. É uma parte da vida sexual masculina que nessa ocasião sucumbe ao recalcamento. [...] O clitóris, quando é ele mesmo excitado por ocasião do ato sexual finalmente consentido, conserva o papel que consiste em transmitir essa excitação às partes femininas vizinhas, um pouco à maneira pela qual as lascas de madeira resinosa podem servir para acender o fogo na madeira mais dura. [...] Quando a excitabilidade erógena foi transferida com sucesso do clitóris para o orifício vaginal, a mulher mudou sua zona principal para aquela que rege sua atividade sexual ulterior, ao passo que o homem conservou a sua desde a infância.” (idem, p.162-164)

Alguns anos mais tarde, em seu texto "A organização genital infantil" (1923/1977), Freud retoma o tema da prevalência do masculino para transformálo em monismo fálico. 
Podemos observar antes de tudo que esse texto deveria se unir ao "Três ensaios" - que, por outro lado, sofreu não poucas modificações: só o texto francês traz quatro delas, ${ }^{1}$ sendo a última posterior à data do aparecimento da "Organização genital infantil". Pois não foi esse o caso. A preocupação de Freud em preservar a unidade do movimento que tentava instituir com os primeiros psicanalistas é uma explicação provável para esse fato, já que os pontos que estamos estudando não deixavam de suscitar reações em seus colegas da época — como nos atuais, aliás.

Nesse texto, já não é o masculino que se impõe, mas sim o falo. Há aí um verdadeiro passo epistemológico (que, para nós, repete a passagem da primeira para a segunda tópica). ${ }^{2}$ Do órgão, passa-se ao significante, isto é, àquilo que simboliza o órgão masculino ereto, seja aquele que está presente em cada criança dos dois sexos, em seus corpos, mas também presente em cada um, independentemente de seu sexo anatômico, como consequência dos efeitos da linguagem na estruturação do psiquismo.

“A característica principal dessa 'organização genital infantil' é, ao mesmo tempo, o que a diferencia da organização genital definitiva do adulto. Consiste nisso em que, para os dois sexos, um único órgão genital representa um papel: o órgão masculino. Não há, portanto, um primado do genital, mas um primado do falo." (FREUD, 1923/1977, p.114)

A conclusão desse texto situa com clareza o momento em que emerge o Feminino — que não tem fundamento antes:

"Não é sem importância representar as transformações que sofre a polaridade sexual que nos é familiar, durante o desenvolvimento sexual infantil. Uma primeira oposição aparece na escolha objetal que, de fato pressupõe sujeito e objeto. No estádio da organização pré-genital sádico-anal, ainda não é questão de masculino e feminino, o que predomina é a oposição entre ativo e passivo. No estádio seguinte, o da organização genital infantil, há bem um masculino, mas não há feminino; a oposição se anuncia aqui: órgão genital masculino ou castrado. Somente quando o desenvolvimento se completa, na época da puberdade, é que a polaridade sexual coincide com masculino e feminino. O masculino reúne o sujeito, a atividade e a posse do pênis; o feminino perpetua o objeto e a passividade. A vagina agora

\footnotetext{
${ }^{1}$ Escrito em 1905, foram introduzidos acréscimos e modificações a este texto em 1910, 1915 , 1920 e 1924, a cada nova edição (excetuadas as de 1922 e 1924, durante a vida de Freud).

${ }^{2}$ Passagem de uma dinâmica mecanicista e termodinâmica para uma perspectiva tópica - e pré-estruturalista — que apela à estrutura da linguagem como organizadora do psiquismo humano.
} 
adquire valor como habitação do pênis, ela recolhe a herança do corpo materno (Mutter Leibes, que pode igualmente ser traduzido por 'entranhas da mãe')”. (FREUD, 1923/1977, p.116)

Em 1932, no texto intitulado "A feminilidade" (1932a/1981), Freud insiste nos dois pontos que nos interessam especialmente. Ele volta, então, ao monismo fálico e à ausência de percepção sexualizada da vagina antes da puberdade:

"Os dois sexos parecem passar pelas fases iniciais do desenvolvimento libidinal de maneira similar. [...] Com a entrada na fase fálica as diferenças entre os sexos se apagam totalmente em favor das coincidências. Devemos reconhecer agora que a menina pequena é um homem. No menino, é sabido que essa fase é caracterizada pelo fato de que ele sabe proporcionar a si mesmo sensações voluptuosas com seu pequeno pênis. E que ele relaciona isso ao estado de excitação deste com suas representações de relações sexuais. A menina faz a mesma coisa com seu clitóris ainda menor. Poderia parecer que nela todos os atos onanistas se efetuam com esse equivalente do pênis, e que a vagina propriamente feminina, para os dois sexos, ainda não foi descoberta. É verdade que há vozes aqui e ali que estão certas de que há sensações vaginais desde o início, mas sua distinção em relação às sensações anais e às margens não deve ser fácil: em qualquer caso, não podem representar papel importante. Podemos reter que na fase fálica da menina o clitóris é a zona erógena principal. Mas não é assim que as coisas devem ficar; com a mudança para a feminilidade, o clitóris deve ceder à vagina, total ou parcialmente, sua sensibilidade e, portanto, sua importância, e estaria aí uma das tarefas a resolver no desenvolvimento da mulher, enquanto o homem, mais favorecido pela sorte, não tem senão que seguir, na época da maturidade sexual, aquilo que já exercia no período da eclosão sexual inicial." (FREUD, 1932a/1981, p.158)

E, quanto à libido essencialmente masculina:

"Chamamos libido à força pulsional da vida sexual. A vida sexual é dominada pela polaridade masculino/feminino; somos então levados a encarar a relação da libido com essa oposição. Não seria surpreendente se se revelasse que a cada sexualidade fosse atribuída sua libido particular; de modo que um tipo de libido buscaria os alvos da vida sexual masculina e outro buscaria os da vida sexual feminina. Mas não é nada disso. Há uma única libido, que é posta a serviço tanto da função sexual masculina quanto da função sexual feminina. Não podemos atribuir um sexo a ela própria. Se quisermos qualificá-la de masculina conforme a equivalência convencional da atividade e da masculinidade, não devemos esquecer que ela representa 
também tendências de alvo passivo. Seja como for, o enunciado 'libido feminina' é totalmente injustificado." (FREUD, 1932a/1981, p.176)

Esse ponto — o deslocamento da zona erógena do clitóris para a vagina — foi causa de numerosos mal-entendidos e desencontros para muitos psicanalistas, mesmo contemporâneos de Freud, tais como Karen Horney, Ernest Jones, Melanie Klein... (ROUDINESCO, 1982/1986). Associado ao monismo fálico da infância e à afirmação de uma libido de natureza masculina, suscitava uma frente de resistência contra o Mestre - que, assim, era percebido como um velho senhor, aureolado com sua potência de inovador, mas ultrapassado antes mesmo de ter terminado sua obra.

Voltamos a encontrar esse aspecto, de um Freud como autor histórico, inflexível a título de seu papel de pioneiro, envelhecido porém, e já obsoleto, tributário de velhos fantasmas insuficientemente elaborados (tais como os laços incestuosos não ultrapassados em relação a sua mãe), em muitos textos de psicanalistas contemporâneos. Por certo isso não é dito exatamente desta maneira, mas a concepção básica está lá. Para nós, esses pontos de vista têm que ser remetidos à ausência de rigor na utilização de seus conceitos, e a permissão de uma leitura de aproximação de seus textos é manifestação disso.

Pensamos que - sem passar pelo endeusamento do personagem e de sua obra - , ao contrário, há um trabalho de exegese a fazer, o qual deve passar pela justa apreciação daquilo que trazem. (Antes de pôr na conta aquilo que poderia constituir obstáculo para sua compreensão.) Devemos tentar ouvir aquilo que ele introduziu, antes de atribuir a erro ou a resistências que lhe seriam próprias. Observemos de passagem que isso deve ser comparado à escuta que temos com nossos pacientes: o que vem a constituir obstáculo a esta deve ser posto na conta da contratransferência, isto é, daquilo que vem barrar a escuta do analista (e não da ininteligibilidade do que o paciente diz). Se há resistência, ela está do lado do leitor, daquele que escuta a palavra de Freud.

Esse trabalho de exegese precisa passar pelos recursos teóricos próprios de seu tempo, isto é, obsoletos agora e ultrapassados (é aí que se encontra o que está ultrapassado). Há, portanto, um trabalho de transposição de si mesmo no tempo, para permitir uma leitura adequada desses textos, historicamente datados; há depois outro trabalho de transposição de sua leitura numa língua levando em conta as aquisições epistemológicas acumuladas desde então - de modo a oferecer aos conceitos freudianos uma atualidade e, portanto, inteligibilidade.

Isso constituiu uma parte do projeto de Lacan. Seus instrumentos foram o estruturalismo e a linguisteria (a distinguir da linguística, que não leva em conta o sujeito do inconsciente). Nessa tarefa ele foi muito ajudado pelo que o próprio Freud tinha esboçado. A facilidade com que puderam ser transpostas as noções 
de deslocamento e condensação (descritas no trabalho do sonho e na gênese das formações do inconsciente) em metonímia e metáfora já oferecia uma plataforma comum imediatamente disponível. A isso se acrescentava o fato de que Freud não parou, ao longo de toda a sua obra, de aludir à importância das palavras para a compreensão das formações do inconsciente (1901/1948) — talvez mesmo nas construções gramaticais cuja declinação encontramos nos pares de opostos dos funcionamentos perversos (FREUD, 1915/1969). Assim, para ele, também o inconsciente era estruturado como uma linguagem.

É nessa perspectiva que é preciso que nos situemos para compreender as duas contribuições de Freud que nos interessam: o deslocamento das zonas erógenas do clitóris para a vagina e o monismo fálico do infantil (que ligamos à libido essencialmente masculina). Há necessidade de convertê-las para lhes dar uma inteligibilidade que permita situá-las no eixo da psicanálise, tal como foi iniciada por seu iniciador (num momento em que os recursos disponíveis em seu tempo só podiam mesmo limitar seus progressos).

\section{RETOMADA DAS DUAS NOÇÕES FREUDIANAS}

Ou, como retomar essas duas contribuições? Quanto à referência exclusivamente fálica na infância, os textos de Freud que tratam da sexualidade infantil sempre desenvolvem essa ideia: não há senão um único sexo no infantil. A criança é totalmente incapaz de apreender o que é do Outro sexo. Para elas, há o sexo do menino e a ausência de sexo de menino nos sujeitos apenas chamados de meninas.

É função das teorias sexuais infantis, com espantoso rigor para crianças tão pequenas, tentar resolver essa equação de duas incógnitas: há um único sexo no simbólico, e dois na realidade! É ainda seu caráter ilusório que se anuncia aqui (trata-se de uma equação impossível), e seu futuro destino: o recalcamento integral, quando uma novidade (a puberal) vier torná-las caducas e obsoletas.

Assim, na menina, o que vai compor sua especificidade parece não ser visto pelos sujeitos dos dois sexos. Ou, se ela existe, é sob o registro da norma estabelecida pela Lei que resulta da alquimia edipiana - que transforma o enigma da diferença dos sexos, para a criança, em ter ou não ter (norma fálica), isto é, em posições especulares em relação ao sexo encarnado pelo falo.

Para dar ênfase à sua mensagem, Freud (1908/1969) vai mesmo evocar a vinda de um extraterrestre que, no mínimo, ficaria imediatamente perplexo pela constatação da existência de dois sexos, tão opostos um ao outro que os sujeitos que são os seus portadores se tornam opostos entre si! Pois bem, para a criança é tudo ao contrário, nos diz Freud: a criança faz tudo para lutar contra 
isso que, no entanto, vê todos os dias — isto é, que há dois sexos anatômicos (independentemente das posições sexuadas possíveis).

A criança é vítima de sua aceitação original e irremediável da linguagem como organizadora de seu mundo interior, e de suas consequências: a saber, que a realidade não é mais percebida senão por meio de um sistema que a organiza (RSI), ${ }^{3}$ e não de uma percepção natural da qual os animais nos dão uma ilustração. Há uma perda irremediável em seguida à entrada do infans na linguagem, que é a de um Saber no real (STEVENS, 1998) — saber quanto à relação sexual, para a qual os animais não precisam de modelo.

Ora, no seio desse sistema, não existe senão um único sexo.

Assim, somente constrangida e forçada, a criança vai admitir que algumas das meninas - as culpadas, de resto as "futuros homens" — poderiam de fato ter um sexo diferente do seu (cortado ou que vai crescer). Sua posição é, ao que parece, retardar ao máximo o dia em que deverá aceitar que sua mãe, ela própria, poderia também ter sido vítima dessa mutilação.

Esse tempo é contemporâneo do edipiano. Trata-se do tempo em que se encontra adiada a questão da diferença dos sexos, remetida a um depois. É a promessa edipiana: "tu também, mais tarde, vais encontrar uma mulher para ti”, aureolada pelo Saber fálico ("tu também saberás mais tarde”). Dentro do referencial do infantil, essa promessa de fato é ouvida como a de um saber que viria dizer o que faz a ligação entre duas pessoas de sexos diferentes, como o que se refere ao relacionamento sexual — que não existe, lembramos aqui.

Assim, o mundo fica pacificado, pois essa diferença é estabelecida por algo exterior a si que funciona e organiza o mundo (a taxonomia, o conhecimento, a Lei). Um saber superior à sua vontade vem, de fato, trazer uma qualificação para a diferença dos sexos. Dessa vez há, sim, dois sexos diferentes, porém garantidos pela lei, e: "mais tarde, eu próprio vou saber alguma coisa sobre isso".

A fase de latência, com seu investimento no conhecimento e nas condutas pseudo-obsessivas, pode ter início.

Dessa maneira, fica estabelecido por Freud o monismo fálico do Infantil. Não é, então, audacioso demais supor que a novidade puberal será o advento do Outro sexo (outro escrito com O maiúsculo, uma vez que radicalmente outro, como já especificamos). É o que chamamos de Feminino. Esse outro sexo é, por dedução, de natureza radicalmente diferente daquele situado no Infantil - o fálico. Não responde, portanto, àquilo que normatizava e ordenava o mundo até a puberdade - a linguagem. O Feminino, portanto, deve ser situado num mais além da linguagem. Não tem correspondência na linguagem.

\footnotetext{
${ }_{3}^{3}$ Real, Simbólico, Imaginário.
} 
De fato, a puberdade se anuncia, e abala todo o equilíbrio precedente. A segunda revolução copernicana (depois da revolução edipiana) se impõe pelo corpo, e vem transbordar a linguagem e o conhecimento, à medida que não encontrará eco aí. O Feminino se impõe como novidade radical, extrafálica, sem equivalente na linguagem, inscrevendo um vazio, uma falta (a que propusemos situar, na nossa introdução, dentro da teoria psicanalítica).

Era exatamente essa a novidade que Freud evocava por meio daquilo que qualificava de deslocamento das zonas erógenas do clitóris para a vagina. E dava o resultado descritivo disso, no nível da erogenização de uma nova zona corporal, isto é, nos fatos - mas sem nada trazer num plano metapsicológico que viesse validar ou explicitar essa hipótese. E não era para menos, pois nada vem qualificar essa novidade dentro da linguagem.

É também assim que se torna inteligível a afirmação freudiana quanto à libido essencialmente masculina. Como poderia ter sido diferente, desde o instante em que nada vem inscrever um caminho feminino, uma vez que nenhum significante permite balizar isso? Somente pode ser inscrita a libido fálica, masculina. A menina se conforma a isso por essência. Mesmo se se diferencia por se desprender disso.

Os recursos teóricos que permitem balizar o que se trata de um compartimento vazio, isto é, do real, não tinham sido difundidos ainda no tempo de Freud. Ele só podia mesmo terminar no "continente negro" do Feminino, sem poder ir mais longe.

Porque, de fato, como abordar no plano teórico algo que escapa à linguagem por sua própria essência? É aqui que se tornam necessárias as contribuições contemporâneas, das quais Freud não tinha conhecimento, e que nós já introduzimos por meio de Lacan: o estruturalismo e a linguisteria.

\section{AS VIAS PRÉ-ESTRUTURALISTA E ESTRUTURALISTA}

Fundada a partir da linguística (SAUSSURE, 1916/1995), a abordagem estruturalista se dispersou ao longo de todo o século XX no conjunto das Ciências Humanas, oferecendo verdadeira renovação da abordagem dos fatos humanos. Seja em antropologia (Claude Lévi-Strauss), em literatura (Roland Barthes), em filosofia (Merleau-Ponty) ou em psicanálise (Jacques Lacan), ${ }^{4}$ (DOSSE, 1992), sua influência foi importante, ao ponto de poder-se identificar o século XX e sua história em torno de seu advento e de suas consequências.

O princípio é oferecer uma radicalidade na definição daquilo que é observado em Ciências Humanas, em termos de signo, pelo fato de que é:

\footnotetext{
${ }^{4}$ Lacan vai se diferenciar desses outros autores ao trazer um importante matiz: a incompletude do Outro.
} 
- Destacado de um referente (realidade);

- Ligado a uma imagem saída da sensorialidade (imagem acústica, chamada significante por Ferdinand de Saussure) e um conceito (chamado significado);

- Separados um do outro pelo arbítrio inscrito sob a forma de barra (s/S);

- Inserido e diferenciado por corte do conjunto dos outros signos presentes que definem seu "valor";

- Independentemente de qualquer historicização das palavras ou dos conceitos (prevalência da sincronia, rejeição da diacronia, da história, da significação e da metafísica);

- Articulado aos outros significantes de acordo com as regras da espacialização (topologia).

Há, assim, dissociação entre um nível da realidade (não levado em conta — referente), um nível imaginário (incluído o conceito e suas valências histórica e metafísica — sentido), ele próprio anulado pela natureza arbitrária de seu laço àquilo que se torna a substância definida e única do estudo estrutural: o significante. O conjunto das ações complexas por meio das quais esse significante se encontra articulado aos demais significantes que o enquadram obedece a leis — às leis da linguagem.

O fato humano muda, então, radicalmente de estatuto. Não é mais necessário dar-lhe significação histórica, filosófica - que a remete para o lado de um imaginário fonte de confusão e de perda — , mas sim considerá-lo como elemento inserido numa trama, formando, com outros elementos similares, uma rede regida pelas regras da articulação da linguagem.

Uma de suas particularidades é a coesão do conjunto, formando uma estrutura. Assim, a modificação de um dos elementos tem efeitos imediatos sobre os outros, a título do equilíbrio topológico que os une. É assim que um traço pode ser deixado, mesmo por um elemento que falta. Uma estrutura dada, dessa maneira, se torna portadora do que a constitui em si mesma, por seus elementos presentes e igualmente pelos ausentes (compartimento vazio), ${ }^{5}$ e seu equilíbrio traz o vestígio daquilo que o constitui. ${ }^{6}$ Ela integra dentro disso uma história e a falta, o desaparecimento, a elisão, o inconsciente...

\footnotetext{
${ }^{5}$ Aquilo que Freud, em sua teoria do sonho, marcava como "o umbigo do sonho".

6 "Em primeiro lugar, uma estrutura oferece um caráter de sistema. Consiste em elementos tais que qualquer modificação de um deles engendra modificação de todos os outros. Em segundo lugar, todo modelo pertence a um grupo de transformações cada uma das quais corresponde a um modelo da mesma família, embora o conjunto dessas transformações constitua um grupo de modelo. Em terceiro lugar, as propriedades indicadas acima permitem prever de que maneira o modelo vai reagir, em caso de modificação de um de seus elementos. Finalmente, o modelo deve ser construído de tal maneira que seu funcionamento possa dar
} 
Outra de suas particularidades é consequência disso: erradicação, como propriedade particular, do imaginário (interno - lembranças, sentidos; externo - realidade, história), considerado fonte de confusão, de perda, de saturação de significações ao ponto de perder aí até mesmo o princípio desta.

Encontramos aí novamente uma das características descritas por Freud a propósito do sonho e de sua produção (FREUD, 1900/1925), ou, mais adiante, da alucinação no bebê que acabou de nascer, quando ela vem no lugar do objeto exterior (1895/1956). A imagem é enganadora, ou, mais exatamente, o imaginário é enganador, e expõe o eu à captação ou à demarcação paranoica. Vem vestir o desejo inconsciente recalcado de seus adornos enganadores, prontos a destruir os efeitos da vigilância da censura, e o princípio de realidade. Vem saturar a coisa adotando, em todos os casos, a aparência e as características daquilo que provém dos sentidos (da sensorialidade) para iludir o Eu e satisfazer a necessidade da realização do desejo inconsciente pelas vias onírica e alucinatória. Engana a consciência empregando as imagens ${ }^{7}$ perceptivas como veículo daquilo que lhe é estrangeiro em seu princípio - as fantasias e sua ambivalência, com seus efeitos de sedução, de brilho, talvez mesmo do horror ou da angústia em caso de fracasso do trabalho do imaginário (pesadelos nos sonhos).

A ideia do sonho a ser lido como uma carta enigmática é a manifestação disso. Cada imagem deste é remetida, pelo jogo das associações livres, a tantos elementos (mais ou menos a completar) ${ }^{8}$ que, articulados entre si, formam uma estrutura de frase, a ser tomada como enunciação do sujeito do inconsciente. De um ponto de partida imaginário (sonho manifesto), chegamos ao conteúdo latente do sonho, correspondente a uma afirmação. ${ }^{9}$ Nesse sentido, Freud é um pré-estruturalista.

conta de todos os fatos observados" (LÉVI-STRAUSS, 1958, p.306).

${ }^{7} \mathrm{O}$ que nos permite diferenciar imagem e imaginário, como função que vem se exercer sobre as imagens para este último.

${ }^{8}$ Cf. Freud (1932b/1936, p.20): "Nós intervimos então pela nossa própria vontade, completamos as alusões, tiramos conclusões irrefutáveis, formulamos aquilo que o paciente apenas trouxe à tona. Isto poderia dar a impressão de que deixamos nosso espírito e nosso bom senso brincar com o material que o sonhador põe à nossa disposição e que abusamos disso para pôr em interpretação naquilo que ele disse e que não deveria ser interpretado"... E Freud nos remete então à literatura sobre o assunto, e à aplicação dessa técnica em nós mesmos "para convencê-los da maneira obrigatória como se desenrola tal trabalho de interpretação".

${ }^{9}$ A interpretação, como elemento acrescentado para dar novamente uma coerência a esse conjunto, encontra aí sua definição: prender, por dedução lógica, estrutural, as exclusões que tal configuração pressupõe - isto é, os significantes cuja exclusão (recalcamento) é necessária para essa constituição dada, para sua coerência como frase. É dessa dedução lógica que a interpretação encontra a única justificação de sua introdução possível naquilo que o paciente diz. De fato, não há outro fundamento teórico nem outra ética possível à interpretação, desde o instante em que se trata de garantir que ela não seja portadora de significantes próprios do psicanalista — talvez mesmo dos passeios de suas fantasias nas de seu paciente. 
Lacan, mais tarde, ampliará essa perspectiva de maneira mais radical ao articular a origem do Eu à instância imaginária, a partir do reflexo da imagem do corpo no espelho (LACAN, 1936/1966). Assim, tudo o que se produz a partir dessa instância — o Eu, a consciência — se torna suspeito, pelo fato do caráter de ilusão e de fraude, de confusão e de dúvida daquilo que o origina, a saber: a via obrigatória do imaginário.

\section{CORPO E ADOLESCÊNCIA}

É com essas contribuições que pode ser possível demarcar a novidade puberal (em outros termos que não aqueles, muito descritivos, de Freud). A novidade puberal deve ser colocada no registro de um real, e que corresponde ao Feminino.

De um real, de fato, à medida que encontra aí seu ponto de partida, e igualmente de chegada, uma vez que não há eco no simbólico a essa novidade.

Do feminino, para retomar os progressos de Freud sobre o monismo fálico do Infantil e o deslocamento das zonas erógenas específicas da puberdade.

Assim, não há Saber sobre o encontro dos sexos e dos sujeitos que se unem. Há ausência de saber que pode ser oposta ao que constitui a novidade puberal nos sujeitos dos dois sexos. O que tinha constituído a promessa edípica (um Saber sobre o que seria um encontro possível), desaparece, levando consigo os pais que eram seus portadores. Da posição deles de oráculos, de ser "aqueles que sabem", eles caem para essa de sujeitos faltantes e submetidos ao enigma que qualificamos de "Feminino".

Esse real puberal é o que vem constituir a novidade. Introduz o Outro sexo com referência àquele que era o único presente no Infantil, o fálico.

A adolescência é, portanto, esse tempo de descoberta da falta e do impossível que atinge o saber sobre o sexo e a relação sexual. É o tempo da destituição dos pais e da instauração da falta como constitutiva do corpo.

O corpo é, então, o primeiro elemento pelo qual se anuncia aquilo que faz a adolescência. É isso ainda, na continuação, quando se impõe como aquilo por que é preciso passar para encontrar o objeto, que essa novidade do Feminino vem convocar, pois não há correspondente simbólico para aquilo que constitui a novidade. É, portanto, aí dentro que há algo a pacificar, a velar. É por seu intérprete que o objeto pode ser encontrado, é na realidade que é preciso agora procurar esse objeto, que pode vir a recobrir - portanto, pacificar - esse efeito de real da novidade puberal. É a busca do outro do Outro sexo, como parceiro encontrado na realidade, e inscrevendo em seu corpo, por meio da diferença dos sexos, que é diferença radical, essa parte de real a recobrir.

A motivação da união em casal dos humanos vem dessa necessidade: trazer uma figurabilidade ilusória ao real puberal pela interposição de um outro na 
realidade. Compreende-se melhor por que o Amor tem natureza imaginária ficando a cargo de cada um cuidar disso de forma que se sustente ao menos uma ilusão para si.

Todos os outros encontros vêm fazer papel de engodo, e podem também ser levados em conta: de fato, tudo o que pode encobrir esse real puberal, trazendo um gozo corporal e a busca repetitiva do objeto. O outro do Outro sexo aparece como o mais adequado (inscrevendo esse real no corporal da diferença dos sexos, e abrindo para uma criatividade - o parto). Estamos aqui no caso de uma toxicomania bem-sucedida, pois a repetição do gozo se faz em relação com o outro. O outro do mesmo sexo é uma versão atenuada disso, pois se trata do encontro do mesmo. Todos os objetos adictivos, de maneira geral, sejam tóxicos (drogas) ou não, podem vir aqui como engodo desse véu: o nada da anorexia constitui exemplo disso.

\section{EXEMPLOS CLÍNICOS}

Boa expressão dessa busca pode ser vista no filme de Robert Bresson, Le pickpocket (1959). O herói se apaixona, quando ainda é estudante e sua mãe está morrendo, por uma atividade que o devora ao ponto de invadir todos os seus instantes: o de batedor de carteiras. Chegado aos extremos (obrigado a fugir da França, uma vez que está sendo procurado pela polícia), ele constata seu erro diante da mulher jovem que se obstina a vir vê-lo ainda, mesmo na prisão — essa mulher jovem que era aquela que vinha avisá-lo do estado de saúde declinante de sua mãe na primeira parte do filme. É então, uma vez preso pela polícia e julgado, que ele se dá conta de que sua verdadeira busca definitivamente era outra, e não aquela que se lhe apresentava com tanta constância: o outro do Outro sexo.

A confrontação ao Feminino na adolescência é uma injustiça ao fálico (conduta de batedor de carteiras), cujo resultado é a abertura ao Feminino e o encontro possível de um outro do Outro sexo.

Outra expressão, mais radical, se encontra no filme Into the wild, de Sean Penn (2007), cujo roteiro resumimos a seguir.

Depois de ter terminado formalmente sua adolescência e seus estudos superiores, o herói do filme escolhe uma atitude surpreendente e radical, posto que adotada à revelia dos que lhe são próximos. Abandonando tudo, até mesmo suas economias, ele se lança numa busca do vazio e da falta. Assim, vai procurar um lugar esvaziado de qualquer vida em comunidade, onde o isolamento e a solidão se repetem num retorno à vida natural. Se aí ele encontra objetos fabricados pelo homem, são aqueles que não têm valor, seja por sua banalidade ou por sua funcionalidade (fuzil, fósforos, livros, caneta, óculos, roupas...), seja 
por sua usura além do reciclável (o ônibus que por acaso encontra e que será seu precioso domicílio).

Ao longo da narração, uma voz em off — a voz de sua irmã — nos faz compreender as casualidades biográficas que conduzem esse rapaz em final de adolescência a um tal questionamento do social e das Leis que o organizam. Seu pai não reconheceu seu filho legítimo (nascido da mulher com a qual estava casado), ao passo que vai reconhecer nosso herói e sua irmã, filhos de sua amante na ocasião (e sua mulher atual). Disputas invasivas pontuam a vida afetiva desse casal. Os pais anunciam aos filhos seu divórcio, de fato sempre falam dele, porém nunca o concretizam.

Em determinada cena do filme, aparece uma articulação entre esses dois pontos de tropeço do comportamento do pai, permitindo pensar que estão ligados em nosso herói. Trata-se de um episódio em que os pais brigam, fisicamente: o pai tenta sujeitar sua mulher por meio de força, enquanto ela se opõe a ele. A discussão, enfurecida, aborda a questão da festa de Natal, que está próxima. O pai, em sua cólera, quer cancelá-la, o que desperta a ironia de sua mulher: ela observa que ele não está no lugar de Deus, para poder eliminar essa festa. Será que ele pode anular o nascimento de um menino (Jesus), como anulou o nascimento de seu primeiro filho?

No caminho desse absoluto, o herói do filme vai encontrar três figuras tutelares, e outras tantas tentações em sua travessia do deserto. Uma primeira mulher, da idade de sua mãe, com a qual ele mantém uma relação de ternura, nunca transbordante apesar dos apelos desta. Outra mulher, desta vez de sua idade, oferece-se a ele na doçura de uma relação que teve tempo para se desenvolver - e que ele recusa com firmeza. Enfim, um homem, da idade de seu avô, cujo carinho e atenção para com nosso herói o levam a propor a este de fazer dele seu único herdeiro. Aí também ele se afirmará, e não aceita a oferta.

Depois dessas três tentações, é o Alasca, em sua atmosfera gelada de inverno, e sua instalação que é favorecida aí pelo encontro de uma carcaça de ônibus, arrumada previamente para abrigar caçadores. Sua vida se preenche com diversas atividades: a leitura de autores-fetiches, como Jack London; a escrita de suas reflexões; por fim, a busca de sua subsistência.

Chega o momento em que ele atinge o objetivo de sua busca, quando pode abandonar essa situação extrema à qual se reduziu durante um tempo iniciático - enquanto seus pais e sua irmã definham de tristeza e remorso. O que vem permitir essa gangorra é uma citação de um de seus autores prediletos, e que é duma banalidade dolorosa: uma ode à amizade, ao amor, à vida simples de família... A continuação do filme é a narrativa do fracasso de seu retorno, e o final infeliz do herói. 
Esse filme vem figurar a necessidade da falta, como condição de uma adolescência possível e do encontro com o outro no social. A falta, saturada por esse pai vivido como Pai da horda primitiva (tem direito de vida ou morte — simbólica — sobre seus filhos), precisava ser construída por esse jovem. É barrando o encontro com o outro, Outro sexo em primeiro lugar, e pela prova da realidade, que ele foi procurá-la — a expensas suas.

Recebido em 17/6/2009. Aprovado em 23/8/2009.

\section{REFERÊNCIAS}

DOSSE, F. (1992) Histoire du structuralisme, Le champ du signe, 1945-1966. Paris: La découverte. FREUD S. (1895/1956) “Esquisse d'une psychologie scientifique", in La naissance de la psychanalyse. Paris: PUF.

FREUD, S. (1900/1925) L’interprétation des rêves. Paris: Gallimard. . (1901/1948) Psychopathologie de la vie quotidienne. Paris: Payot. (1905/1987) Trois essais sur la théorie sexuelle, trad. Francesa de P.Koeppel. Paris: NRF/Gallimard.

. (1908/1969) "Les théories sexuelles infantiles", in

La vie sexuelle. Paris: PUF.

. (1915/1940) "Les pulsions et leurs destins", in Métapsychologie. Paris: Gallimard.

. (1923/1977), “L’organisation génitale infantile”, trad. francesa de. J. Laplanche”, 3 ed. In La vie sexuelle. Paris: PUF.

. (1932ª1981) “La féminité", in Nouvelles conférences sur la psychanalyse, trad. Francesa de A. Berman. Paris: Gallimard (Col. Idées) mard.

(1932b/1936) Nouvelles conférences sur la psychanalyse. Paris: Galli-

LACAN, J. (1936-1966) "Le stade du miroir comme formateur de la fonction du Je telle qu'elle nous est révélée dans l'expérience psychanalytique". In: Ecrits. Paris: Seuil.

LEVI-STRAUSS, C. (1958) Anthropologie structurale. Paris: Plon.

ROUDINESCO, Elisabeth (1982/1986) L'histoire de la psychanalyse en France, 2 ed. La Bataille de cent ans, Vol. 1. Paris: Seuil/Ramsay.

SAUSSURE, F. (1916/1995) Cours de linguistique générale, Paris: Grande bibl. Payot, Essai.

STEVENS, A. (1998) Conferência na Universidade Paris VIII (texto estabelecido por Isabelle Finkel).

Olivier Ouvry

ouvry@club-internet.fr 